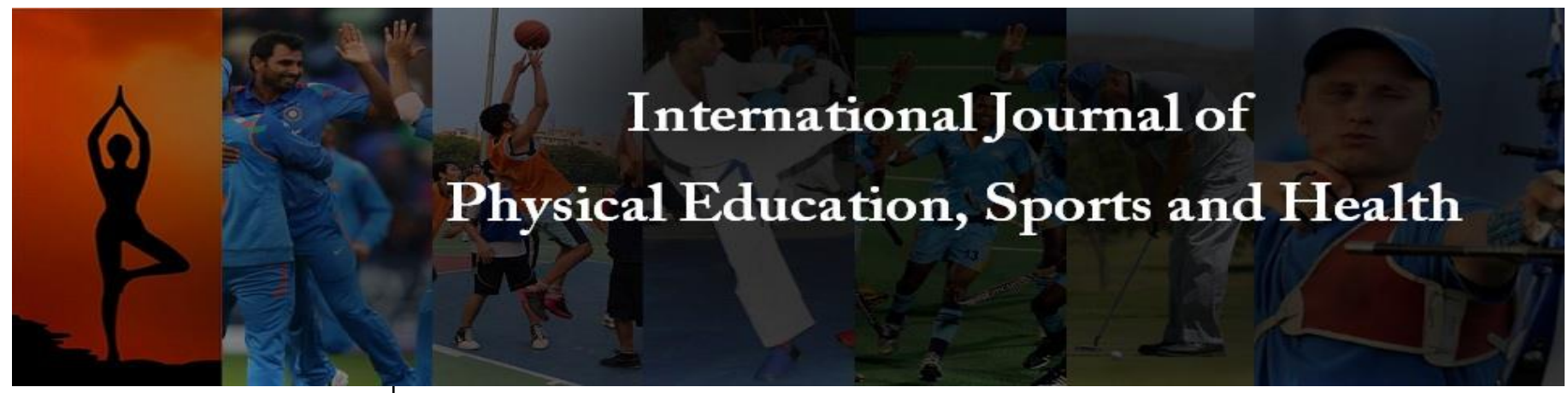

P-ISSN: 2394-1685

E-ISSN: 2394-1693

Impact Factor (ISRA): 5.38

IJPESH 2020; 7(6): 29-33

(C) 2020 IJPESH

www.kheljournal.com

Received: 21-08-2020

Accepted: 19-10-2020

Dr. Tejinder Singh

Assistant Professor, P.G.S. Govt.

College of Physical Education,

Patiala, Punjab, India
Corresponding Author: Dr. Tejinder Singh

Assistant Professor, P.G.S. Govt College of Physical Education,

Patiala, Punjab, India

\section{Comparative analysis of Cardio-vascular endurance between the male raiders and stoppers of circle style kabaddi}

\section{Dr. Tejinder Singh}

DOI: $\underline{\text { https://doi.org/10.22271/kheljournal.2020.v7.i6a.1894 }}$

\section{Abstract}

The purpose of this study was to compare Cardio-Vascular endurance between the male raiders and stoppers of circle style kabbadi. With the purposive sampling technique a total two hundred sixteen (103 raiders and 113 stoppers) of circle style kabaddi were taken as subjects. The results were obtained through the SPSS version 21.0. In this study the 600 Meters Run Test was used to measure the CardioVascular endurance of the players. The study had been analyzed with the help of mean, SD, Levene's test for equality of variances and the comparison between groups was done with the help of t-test. The study revealed that on the basis of the finding male raiders and stoppers were not possessing same degree of Cardio-Vascular endurance and raiders have more ability of Cardio-Vascular endurance than stoppers.

Keywords: Cardio-vascular endurance, raider, stopper, circle style kabaddi

\section{Introduction}

Williams (1962) ${ }^{[7]}$ cleared about physical fitness that physical fitness is essential not only in terms of general health, but also for the special physical requirements for competitive sports and certain highly specialized and demanding occupations.

There are different requirements of physical fitness for different games. A gymnast has different degree of Cardio-vascular endurance than a basketball or football player. Different degrees of different physical fitness components are required for different games or events. A player who has physical fitness according to his game can do better training of the game.

The greater degree of physical fitness is required for the high level performance in the sports and games. The player can be injured during the training or competition if he has not high level physical fitness. Circle style kabaddi requires a high level physical fitness. This game is a combative game and during the completion the body parts of the players take high level stressing. Due to the high level stressing the players are often injured in this game. For avoiding the injuries the player should be proper physically fit.

Physical fitness gives the good feeling to the players and it increases the self-confidence of the players. Self-confidence plays a very important role for the better performance in the games. Physical fitness is a ability to tolerate the more stress of physical load. A fit player can continue the training or play under difficult circumstances whereas unfit player would quit under difficult circumstances.

Circle Style Kabaddi is an indigenous game of the Punjab region. People were playing Kabaddi with some variations in different areas of Punjab and had entertained but now all types of Kabaddi which were played in ancient Punjab have merged into the Circle Style Kabaddi. Circle Style Kabaddi is different from the National Style Kabaddi. This game is played in a circular type playfield instead the rectangular playfield of National Style Kabaddi. When a stopper touches the raider or raider touches any stopper, the other stopper can't touch or stop to the raider. The struggle will be only in two apposite sides' players.

So many studies has been completed on physical fitness or comparative study of physical fitness components between the players of many games. Singh, T. $(2019)^{[5,6]}$. Comparative analysis of speed and muscular power between the male raiders and stoppers of circle style 
kabaddi, Singh, T. $(2018)^{[3,4]}$. Constructed and standardized a specific physical fitness test battery for circle style kabaddi players, Suman Rani (2018) ${ }^{[1]}$ conducted a comparative study of flexibility between kabaddi and kho-kho games players, Singh, T. (2018) ${ }^{[3,4]}$ conducted a comparative study of cardio-vascular endurance, agility and flexibility level between the circle style male kabaddi players of Panjab University Chandigarh and kurukshetra University kurukshetra, Singh, S. Dr. (2017) ${ }^{[2]}$ conducted a comparative study of selected motor fitness components between interuniversity and inter-college male Kabaddi players.

Cardio-Vascular endurance is also play a very important role for the players of circle style kabaddi. Circle style kabaddi players should have the higher rate of Cardio-Vascular Endurance so that they can do continue efforts during the 30 seconds raid again and again in the match. Many players do struggle continue in every raid or in many raids to win the match. The players who have not required Cardio-vascular Endurance's level, they can't maintain their performance level in the whole match.

\section{Method and procedure}

Sample: Total two hundred sixteen (103 raiders and 113 stoppers) subjects of this study were selected with the purposive sampling technique from eight teams which were qualified for the league stage of the inter college Kabaddi Circle Style tournament of selected universities i.e. Panjab University Chandigarh, Punjabi University Patiala, Guru Nanak Dev University Amritsar and Kurukshetra University Kurukshetra.

Selection of Variables: Cardio-Vascular endurance level considered as a variable for this study. 600 meters run test was selected for measuring cardio-vascular endurance level of male raiders and stoppers of circle style kabaddi. This tool was taken from the specific physical fitness test battery for circle style kabaddi players, standardized by Mr. Tejinder Singh $(2018)^{[3,4]}$.

Hypothesis: It was hypothesized that there would be significant difference between male raiders and stoppers of Circle Style kabaddi on Cardio-Vascular endurance level.

Procedure of tests: All participant were informed of the procedure and purpose the experiment and were required to sign and important consent to participate in the study. CardioVascular endurance was measured by 600 meters run test. Score for 600 meters run test was taken in seconds.

Statistical Procedure: In order to compare the cardiovascular endurance level of male raiders and stoppers of circle style kabaddi, the independent t-test was employed. The level of significance chosen to test the hypothesis was $0.05, \mathrm{P}<$ 0.05. For Statistical Description the Statistical Package for Social Sciences (SPSS), version 21.0 was used.

Analysis of data: In the present study analysis and interpretation of the data and results obtained through the application of statistics. This part is devoted to the comparative result of the male raiders and stoppers of Circle Style Kabaddi of selected Cardio-Vascular endurance component. The results had been discussed in two sections. Section-I deals with the statistical description of means and Std. Deviation of the scores of raiders \& stoppers. Section II deals with the comparative result of Cardio-Vascular Endurance of the raiders \& stoppers. This section have been discussed with the help of t-ratio.

\section{Section: I}

Table 1: Shows the mean \& Std. Deviation of the test of the raiders and stoppers in group statistics.

\begin{tabular}{|c|c|c|c|c|c|c|}
\hline \multicolumn{6}{|c|}{ Group Statistics } \\
\hline \multicolumn{2}{|c|}{ Group } & N & Unit & Mean & $\begin{array}{c}\text { Std. } \\
\text { Deviation }\end{array}$ & $\begin{array}{c}\text { Std. Error } \\
\text { Mean }\end{array}$ \\
\hline $\begin{array}{c}\text { 600 Meters } \\
\text { Run }\end{array}$ & Raiders & 103 & Seconds 141.74 & 16.14 & 1.59 \\
\hline
\end{tabular}

Statistical Description of Mean and SD of the test of male raiders and stoppers of Circle Style kabaddi

Table-1 shows the mean \& Std. Deviation of the test of the raiders and stoppers in group statistics. The output shows that the mean \& Std. Deviation of score for 600 Meters Run Test of raiders were $141.74 \& 16.14$ versus $146.29 \& 17.82$ for stoppers.

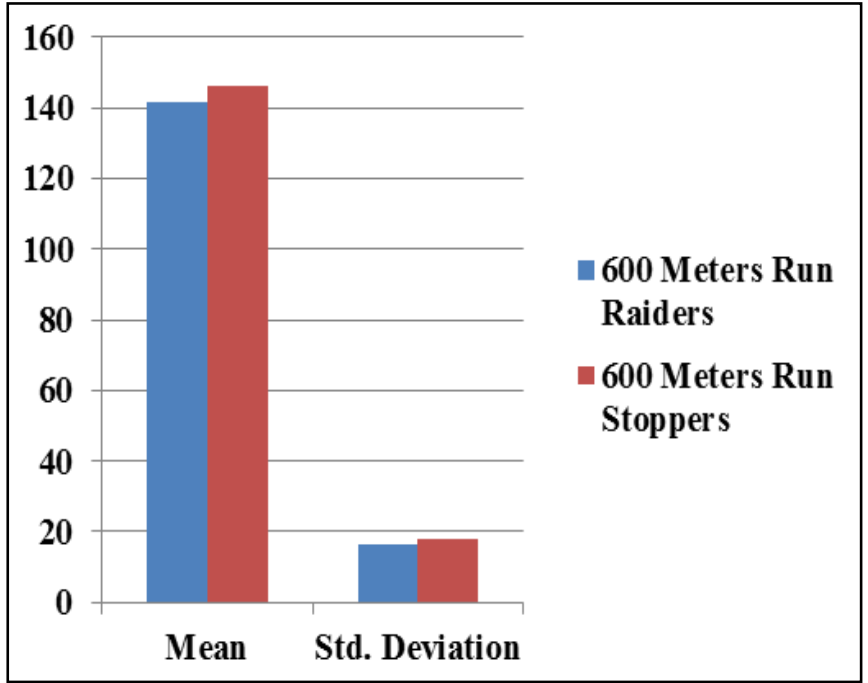

Graph 1: Graphical presentation of Mean and SD of the test of male raiders and stoppers of Circle Style kabaddi

Section 2: This section presents the comparison of CardioVascular endurance between the male raiders and stoppers of Circle Style kabaddi. The comparison with the significance of difference between means score of the raiders and stoppers on selected variable is presented in Table No. 2.

Statistical Description- Significance of difference between means score with $t$-test of male raiders and stoppers of Circle Style kabaddi

Table 2: This section presents the comparison of Cardio-Vascular endurance between the male raiders and stoppers of Circle Style kabaddi.

\begin{tabular}{|c|c|c|c|c|c|c|c|}
\hline \multicolumn{8}{|c|}{ Independent Samples Test } \\
\hline & \multicolumn{2}{|c|}{ Levene's Test for Equality of Variances } & \multicolumn{5}{|c|}{ t-test for Equality of Means } \\
\hline & $\mathbf{F}$ & Sig. & $\mathbf{t}$ & df & Sig. (2-tailed) & $\begin{array}{c}\text { Mean } \\
\text { Difference }\end{array}$ & $\begin{array}{l}\text { Std. Error } \\
\text { Difference }\end{array}$ \\
\hline 600 Meters Run Equal variances assumed & 3.117 & .079 & -1.962 & 214 & .051 & -4.55 & 2.32 \\
\hline
\end{tabular}


The sig. of Levene's test for equality of variances is more than 0.05 for 600 Meters Run Test, So the first rows (Equal variances assumed) was selected for the test.

Interpretation of the t-test results: $t$-test was employed to find out the significance difference between means. The significance level was set at .05 levels. The p-value given by SPSS is 2-tailed, but according to hypothesis there was a need to divide it in half for a 1-tailed test. According to the table-2 the 1-tailed p-value for 600 Meters Run Test is $0.051 / 2=0.025$.

Findings: As per the result depicted in Table-2 shows that The p-values for 600 Meters Run Test was less than 0.05. So, there was a statistical significance difference between the male raiders and stoppers of Circle Style kabaddi in the Cardio-Vascular endurance.

Raw data of Raiders and Stoppers

\begin{tabular}{|c|c|c|c|}
\hline Raiders & $600 \mathrm{M} R$ in Seconds & Stoppers & $600 \mathrm{M} \mathrm{R}$ in Seconds \\
\hline Sukhdeep Singh & 136.2 & Avtar Singh & 143.4 \\
\hline Sandeep singh & 134.4 & Parminder Singh & 121.2 \\
\hline Gurpreet Singh & 123.6 & Asif Mohmmad & 142.8 \\
\hline Rajakaranveer Singh & 160.8 & Balkarn Singh & 141.6 \\
\hline Satnam Singh & 127.8 & Pardeep Singh & 137.4 \\
\hline Harmanpreet Singh & 142.2 & Jaskirat singh & 140.4 \\
\hline Mandeep Singh & 125.4 & Rajwinder Singh & 130.8 \\
\hline Gagandeep Singh & 131.4 & Sandeep Singh & 133.8 \\
\hline Karanbarinder Singh & 133.2 & Gursewak Singh & 144.6 \\
\hline Gagandeep Singh & 129 & Harmanjit Singh & 132.6 \\
\hline Gursimran Singh & 131.4 & Hardeep Singh & 128.4 \\
\hline Jaspinder Singh & 131.4 & Ramanpreet Singh & 142.8 \\
\hline Vatandeep Singh & 123 & Jaskirt Singh & 138.6 \\
\hline Jasmeet Singh & 144.6 & Darshan Singh & 123 \\
\hline Preetpal Singh & 144.6 & Harmeet Singh & 126.6 \\
\hline Manjot Singh & 144 & Karanpreet Singh & 124.2 \\
\hline Baljit Sharma & 130.2 & Balwant singh & 137.4 \\
\hline Jagmeet Singh & 131.4 & Amtojsran & 144.6 \\
\hline Balwant Singh & 142.8 & Shyam Sunder & 129 \\
\hline Parminder Singh & 142.8 & Karmjit Singh & 126.6 \\
\hline Satnam Singh & 135.6 & Major Singh & 139.8 \\
\hline Sarabjit Singh & 121.2 & Kuldeep Singh & 141 \\
\hline Mandeep Singh & 143.4 & Sukhwant Singh & 138.6 \\
\hline Tejinder Singh & 138 & Karanbir Singh & 120.6 \\
\hline Amanpreet Singh & 120.6 & Arandeep Singh & 135 \\
\hline Rupinder Singh & 178.8 & Akashdeep Singh & 141 \\
\hline Raman Kumar & 135 & Sukhwinder Singh & 141 \\
\hline Saranpreet Singh & 131.4 & Hardeep Singh & 147 \\
\hline Ravandeep Singh & 154.8 & Pargat Singh & 128.4 \\
\hline Manjobanjeet Singh & 130.8 & Gurwinder Singh & 136.8 \\
\hline Pawandeep Singh & 141.6 & Amritpal Singh & 174.6 \\
\hline Jaspal Singh & 144.6 & Angrej Singh & 153.6 \\
\hline Amansud & 133.8 & Mandeep Singh & 157.8 \\
\hline Honey Deol & 138.6 & Amritveer Singh & 174.6 \\
\hline Karanpreet Singh & 147.6 & Sulinder Singh & 130.2 \\
\hline Manjinder Singh & 140.4 & Harmanpreet Singh & 143.4 \\
\hline Ravinderpal Singh & 143.4 & Gurpreet Singh & 144 \\
\hline Mandeep Singh & 165 & Gurpinderjit Singh & 179.4 \\
\hline Manpreet Singh & 137.4 & Satpal singh & 139.8 \\
\hline Mandeep Singh & 173.4 & Jaskiranjit Singh & 172.2 \\
\hline Arabdeep Singh & 182.4 & Sarbjit Singh & 138.6 \\
\hline Nirmal Singh & 160.8 & Karamjit Singh & 167.4 \\
\hline Dilsher Singh & 175.8 & Balraj Singh & 140.4 \\
\hline Gurlal Singh & 172.8 & Jaspal Singh & 165.6 \\
\hline Jugraj Singh & 169.8 & Gurpreet Singh & 182.4 \\
\hline Jaimal Singh & 175.8 & Lovepreet Singh & 180.6 \\
\hline Paramjit Singh & 173.4 & Maninder Singh & 168 \\
\hline Malkit Singh & 131.4 & Gursajjan Singh & 177 \\
\hline Gurdas Singh & 163.8 & Amritpal Singh & 171.6 \\
\hline Arjun Singh & 125.4 & Jasbir Singh & 179.4 \\
\hline Sandeep Singh & 182.4 & Manpreet Singh & 181.2 \\
\hline Lovejinder Singh & 153 & Kulwinder Singh & 161.4 \\
\hline Manpreet Singh & 176.4 & Kawaljit Singh & 168.6 \\
\hline Manjinder Singh & 130.8 & Jugraj Singh & 163.2 \\
\hline Parminder Singh & 129 & Robinpreet singh & 165.6 \\
\hline Gurdeep Singh & 141.6 & khusdeep Singh & 181.2 \\
\hline
\end{tabular}




\begin{tabular}{|c|c|c|c|}
\hline Ramandeep Singh & 130.8 & Sapinder Singh & 132.6 \\
\hline Gurwinder Singh & 140.4 & Vizen Kumar & 133.8 \\
\hline Kulwinder Singh & 136.8 & Amritpal Singh & 136.2 \\
\hline Devinder Singh & 132.6 & Punjab Singh & 121.2 \\
\hline Rajwant Singh & 126 & Kamalpreet Singh & 138.6 \\
\hline Kulwinder Singh & 123.6 & Sheetal Singh & 178.2 \\
\hline Hardavinder Singh & 137.4 & Kulwinder Singh & 141.6 \\
\hline Sukhjeet Singh & 139.8 & Rajwinder Singh & 127.8 \\
\hline Lakhveer Singh & 138.6 & Mandeep Singh & 136.8 \\
\hline Sukhveer Singh & 134.4 & Chand Singh & 137.4 \\
\hline Amarpreet Singh & 140.4 & Harman Singh & 131.4 \\
\hline Gurtej Singh & 144.6 & Gurik Singh & 142.2 \\
\hline Rupinder Singh & 141.6 & Harmandeep Singh & 132 \\
\hline Sukhpreet Singh & 123 & Jagpal Singh & 174.6 \\
\hline Sukhchain Singh & 135 & Inderjeet Singh & 136.2 \\
\hline Gurwinder Singh & 139.8 & Amritpal Singh & 124.8 \\
\hline Harjaspreet Singh & 141.6 & Satnam Singh & 133.8 \\
\hline Sukhpreet Singh & 126.6 & Parminder Singh & 136.8 \\
\hline Bhupinder Singh & 127.2 & Randhir Singh & 129.6 \\
\hline Ramandeep Singh & 129 & Amanjot Singh & 136.2 \\
\hline Iqbal Singh & 137.4 & Pawanvir Singh & 124.2 \\
\hline Manpreet Singh & 136.8 & Harjinder Singh & 156.6 \\
\hline Jashandeep Singh & 165.6 & Gurkarmpal Singh & 180 \\
\hline Jaspreet Singh & 178.2 & Gurmeet Singh & 129 \\
\hline Sonu Kumar & 129.6 & Jaspreet Singh & 138 \\
\hline Anil Kumar & 136.8 & Surinder Singh & 140.4 \\
\hline Naresh Kumar & 125.4 & Gurlamber Singh & 136.8 \\
\hline Ankush & 159 & Gurparkash Singh & 135.6 \\
\hline Parveen & 142.2 & Amandeep Singh & 144 \\
\hline Yadvinder Singh & 141 & Vikram & 132 \\
\hline Harinder Singh & 179.4 & Gurdeep Singh & 129.6 \\
\hline Gurjinder Singh & 135.6 & Sonu & 138.6 \\
\hline Ravi Parkash & 128.4 & Tinka & 137.4 \\
\hline Naresh Kumar & 138 & Gourav & 174.6 \\
\hline Naresh & 140.4 & Ramesh & 132.6 \\
\hline Jaydeep & 129 & Amandeep & 136.2 \\
\hline Vijay Goyat & 141.6 & Sonu & 141 \\
\hline Jagdeep & 168.6 & Anuj & 139.2 \\
\hline Sukhbir & 132.6 & Ramesh Kumar & 178.8 \\
\hline Parvesh & 131.4 & Mohan & 144.6 \\
\hline Amit Kumar & 128.4 & Deepak & 176.4 \\
\hline Kuldeep & 127.8 & Vikki Singh & 180.6 \\
\hline Dinesh & 130.8 & Mohan & 136.8 \\
\hline Hari Ram & 131.4 & Anuj Lohan & 130.8 \\
\hline Hemant Kumar & 127.2 & parveen & 144 \\
\hline Sunny & 124.8 & Ashish & 133.2 \\
\hline \multirow[t]{11}{*}{ Aman Kumar } & 152.4 & Naveen & 145.2 \\
\hline & & Robin & 176.4 \\
\hline & & Rakesh & 171 \\
\hline & & Ankit Kumar & 148.8 \\
\hline & & Amit & 178.2 \\
\hline & & Ajay & 138 \\
\hline & & Mohit Shukla & 150.6 \\
\hline & & Nikit & 144.6 \\
\hline & & Sahil & 150 \\
\hline & & Subham & 125.4 \\
\hline & & Gaurav Kamboj & 149.4 \\
\hline
\end{tabular}

Conclusion: The findings of the study can be concluded as under: On the basis of $\mathrm{t}$-test applied the finding of the study concluded that there was a statistical significance difference on 600 Meters Run Test and the hypothesis was accepted. So, raiders and stoppers have not the same Cardio-Vascular endurance. The raiders have more ability of Cardio-Vascular endurance than stoppers.

\section{References}

1. Rani S. A comparative study of flexibility between kabaddi and kho-kho games players, International Journal of Yoga, Physiotherapy and Physical Education 2018, $3(2)$.

2. Singh S. Dr. A comparative study of selected motor fitness components between inter-university and intercollege male Kabaddi players, International Journal of Yoga, Physiotherapy and Physical Education 2017;2(6):65-67.

3. Singh T. A Comparative Study of Cardio-Vascular Endurance, Agility and Flexibility Level between the 
Circle Style Male Kabaddi Players of PU Chandigarh and KU Kurukshetra, Online International Interdisciplinary Research Journal, \{Bi-Monthly\}, ISSN 2249-9598, Volume-08, Sept 2018 Special Issue (02).

4. Singh T. Construction and Standardization of Specific Physical Fitness Test Battery for Circle Style Kabaddi Players, International Journal of Physical Education and Sports Sciences 2018, 13(07). ISSN 2231-3745.

5. Singh T. Comparative analysis of speed and muscular power between the male raiders and stoppers of circle style kabaddi, International Journal of Physical Education, Sports and Health 2019;6(4):148-153.

6. Singh T. Comparative Analysis of Agility and Reaction Ability between the male Raiders and Stoppers of Circle Style Kabaddi, ICPSHF 2019, organized by Physical Education Department of Punjabi University Patiala 2019.

7. Williams JCP. Sports medicine, London: Edward Arnold Ltd 1962, 1. 